\title{
The mineralization characteristics of organic carbon and particle composition analysis in reconstructed soil with different proportions of soft rock and sand
}

\author{
Zhen Guo $^{1,2,3,4}$, Jichang Han ${ }^{1,2,3,4}$, Yan Xu ${ }^{1,2}$, Yangjie Lu ${ }^{1,2}$, Chendi Shi ${ }^{1,2}$, Lei Ge ${ }^{1,2}$, Tingting Cao ${ }^{\text {Corresp., 1, 2, 3,4 }}$, Juan \\ Li $^{\text {Corresp. } 1,2,3,4}$ \\ ${ }^{1}$ Shaanxi Provincial Land Engineering Construction Group Co., Ltd./Shaanxi Key Laboratory of Land Consolidation, Xi'an, Shaanxi, China \\ 2 Institute of Land Engineering and Technology, Shaanxi Provincial Land Engineering Construction Group Co., Ltd., Xi'an, Shaanxi, China \\ 3 Key Laboratory of Degraded and Unused Land Consolidation Engineering, the Ministry of Natural and Resources of China, Xi'an, Shaanxi, China \\ 4 Shaanxi Provincial Land Consolidation Engineering Technology Research Center, Xi'an, Shaanxi, China \\ Corresponding Authors: Tingting Cao, Juan Li \\ Email address: djyjygz2019@139.com,2644816206@qq.com
}

The organic carbon mineralization process reflects the release intensity of soil $\mathrm{CO}_{2}$. Therefore, the study of organic carbon mineralization and particle composition analysis of s oft rock and sand comp ound soil can provide technical support and a theoretical basis for soil organic reconstruction (soil structure, materials and biological nutrition). Based on previous research, four treatments were selected: CK (soft rock:sand=0:1), C1 (soft rock:sand=1:5), C2 (soft rock:sand=1:2) and C3 (soft rock:sand=1:1), respectively. Specifically, we analyzed the organic carbon mineralization process and soil particle composition by lye absorption, laser granulometer, and scanning electron microscope. The results showed that there was no significant difference in organic carbon content between $\mathrm{C} 1, \mathrm{C} 2$, and $\mathrm{C} 3$ treatments, but they were significantly higher than in the $\mathrm{CK}$ treatment $(P<0.05)$. The organic carbon mineralization rate in each treatment accords with a logarithmic function throughout the incubation period $(P<0.01)$, which can be divided into a rapid decline phase in days 1 to 11 followed by a steady decline phase in days 11 to 30. The cumulative mineralization on the 11 th day reached $54.96 \%-74.44 \%$ of the total mineralization amount. At the end of the incubation, the cumulative mineralization and potential mineralizable organic carbon content of the $\mathrm{C} 1, \mathrm{C} 2$ and $\mathrm{C} 3$ treatments were significantly higher than those of the CK treatment. T he cumulative mineralization rate was also the lowest in the $\mathrm{C} 1$ and $\mathrm{C} 2$ treatment. The turnover rate constant of soil organic carbon in each treatment was significantly lower than that of the CK treatment, and the residence time increased. With the increase of volume fraction of soft rock, the content of silt and clay particles increase d gradually, the texture of soil change $d$ from sandy soil to sandy loam, loam, and silty loam, respectively. With the 
increase of small particles, the structure of soil appear ed to collapse when the volume ratio of soft rock was $50 \%$. A comprehensive mineralization index and scanning electron microscopy analysis, when the ratio of soft rock to sand volume was $1: 5-1: 2$, this can effectively increase the accumulation of soil organic carbon. Then, the distribution of soil particles was more uniform, the soil structure was stable (not collapsed), and the mineralization level of unit organic carbon was lower. Our research results have practical significance for the large area popularization of soft rock and sand compound technology. 
1 The mineralization characteristics of organic carbon and particle composition analysis in

2 reconstructed soil with different proportions of soft rock and sand

3

4 Zhen Guo ${ }^{1,2,3,4}$, Jichang Han ${ }^{1,2,3,4}$, Yan Xu${ }^{1,2}$, Yangjie Lu ${ }^{1,2}$, Chendi Shi ${ }^{1,2}$, Lei Ge ${ }^{1,2}$, Tingting Cao ${ }^{1,2,3,4^{*}}$,

5 Juan $\mathbf{L i}^{1,2,3,4^{*}}$

6

$7 \quad{ }^{1}$ Shaanxi Provincial Land Engineering Construction Group Co., Ltd./Shaanxi Key Laboratory of Land

8 Consolidation, Shaanxi, Xi'an, China

$9 \quad{ }^{2}$ Institute of Land Engineering and Technology, Shaanxi Provincial Land Engineering Construction

10 Group Co., Ltd., Shaanxi, Xi'an, China

$11{ }^{3}$ Key Laboratory of Degraded and Unused Land Consolidation Engineering, the Ministry of Natural and

12 Resources of China, Shaanxi, Xi'an, China

$13{ }^{4}$ Shaanxi Provincial Land Consolidation Engineering Technology Research Center, Shaanxi, Xi'an,

14 China

15

16 *Corresponding author: djyjygz2019@139.com; 2644816206@qq.com

18 Short title: Soil organic carbon mineralization 


\section{Abstract}

24

The organic carbon mineralization process reflects the release intensity of soil $\mathrm{CO}_{2}$. Therefore, the study of organic carbon mineralization and particle composition analysis of soft rock and sand compound soil can provide technical support and a theoretical basis for soil organic reconstruction (soil structure, materials and biological nutrition). Based on previous research, four treatments were selected: CK (soft rock:sand=0:1), C1 (soft rock:sand=1:5), C2 (soft rock:sand=1:2) and C3 (soft rock:sand=1:1), respectively. Specifically, we analyzed the organic carbon mineralization process and soil particle composition by lye absorption, laser granulometer, and scanning electron microscope. The results showed that there was no significant difference in organic carbon content between $\mathrm{C} 1, \mathrm{C} 2$, and $\mathrm{C} 3$ treatments, but they were significantly higher than in the $\mathrm{CK}$ treatment $(\mathrm{P}<0.05)$. The organic carbon mineralization rate in each treatment accords with a logarithmic function throughout the incubation period $(\mathrm{P}<0.01)$, which can be divided into a rapid decline phase in days 1 to 11 followed by a steady decline phase in days 11 to 30. The cumulative mineralization on the 11 th day reached $54.96 \%-74.44 \%$ of the total mineralization amount. At the end of the incubation, the cumulative mineralization and potential mineralizable organic carbon content of the $\mathrm{C} 1, \mathrm{C} 2$ and $\mathrm{C} 3$ treatments were significantly higher than those of the $\mathrm{CK}$ treatment. The cumulative mineralization rate was also the lowest in the $\mathrm{C} 1$ and $\mathrm{C} 2$ treatment. The turnover rate constant of soil organic carbon in each treatment was significantly lower than that of the CK treatment, and the residence time increased. With the increase of volume fraction of soft rock, the content of silt and clay 
41 particles increased gradually, the texture of soil changed from sandy soil to sandy loam, loam, and silty

42 loam, respectively. With the increase of small particles, the structure of soil appeared to collapse when the

43 volume ratio of soft rock was $50 \%$. A comprehensive mineralization index and scanning electron

44 microscopy analysis, when the ratio of soft rock to sand volume was 1:5-1:2, this can effectively increase

45 the accumulation of soil organic carbon. Then, the distribution of soil particles was more uniform, the soil

46 structure was stable (not collapsed), and the mineralization level of unit organic carbon was lower. Our

47 research results have practical significance for the large area popularization of soft rock and sand compound

48 technology.

\section{INTRODUCTION}

The farmland soil organic carbon pool plays an important role not only in the process of global carbon

circulation but also as the most important material base for soil fertility (Pan et al., 2009), and has a decisive

role among others in the maintenance of cultivated land productivity, the prevention and treatment of soil

erosion, the spatial and temporal variation of soil respiration, and its stability (Tommaso et al., 2018). The

soil organic carbon pool in terrestrial ecosystems is about three times that of the plant carbon pools (Lal,

2004). The organic carbon exchanged between soil and atmosphere accounts for about $2 / 3$ of the total

carbon storage of surface ecosystems, which slightly changed in recent years because of the impact of greenhouse gas emissions (Lal, 2004). Soil organic carbon mineralization is an important part of the carbon cycle in terrestrial ecosystems. The change in land resources by human activities causes changes in atmospheric $\mathrm{CO}_{2}$ concentration through the effects on terrestrial ecosystems which in turn affects the carbon 
62

human activities has attracted much attention in recent years and has become the core issue of multidisciplinary research (Feng et al., 2006; Schmitz et al., 2017; Zhang et al., 2018).

Soil organic carbon mineralization is a process in which organic substances are decomposed into inorganic substances by microbial degradation, providing nutrients for crop growth, and releasing greenhouse gases such as $\mathrm{CO}_{2}$ (Dai et al., 2017; Guo et al., 2018). Current studies have shown that arid and semi-arid regions account for $41 \%$ of the global land area, carrying $38 \%$ of the human population, and which are sensitive to global climate change and human activities (Zhou and Zhang, 2009). Experts call it the arid and semi-arid areas of Shaanxi, Shanxi, Inner Mongolia and other arid areas "Earth Environment Cancer", since these important soil resources exhibit serious soil and water loss, loss of soil texture, low nutrient content and poor structure. This can be seen as a geographical hazard of the soft rock and sand areas and it determines the urgency and difficulty of ecological restoration in the region (Wang et al., 2007). Han et al. (2012) studied the structure and physicochemical properties (including capillary porosity, saturated hydraulic conductivity, organic matter, water-stable aggregates, mineral composition, and crop yield) of soft rock and sand and realized that the two soil forms can be mixed into different proportions to form a "new soil". They also suggested that the optimal compounding ratio for crop growth ranged between 1:5 and 1:1 (soft rock: sand). Presently, the technology of compounding of soft rock and sand into soil is widely used, and the newly added cultivated land amounts to 1573 ha, which realized the resource utilization of soft rock and improved the regional ecological environment (Han et al., 2012). She et al. (2015) studied the nutrient content and hydraulic parameters of the soft rock and sand compound soil, and proposed that the fertilizer retention performance of the compound soil can be effectively improved with an increase of the soft rock content, whereas the available nutrient content can be improved with sufficient 
83

84

water. Wang (2016) mixed sand and soft rock to a certain proportion forming a new type of soil, analyzed its textural changes and biochemical indexes of crops, and discussed the soil texture changes from sand to silt loam as the proportion of soft rock increased. Moreover, the photosynthesis rate of crops and the activity indexes of antioxidant enzymes increased at the beginning and then decreased. However, considering the present global warming, we should not only improve the utilization rate of waste resources but also maintain the sustainable development of ecological environment. The issue of greenhouse gas emissions from the compounded soil is an area which has not yet been considered by researchers. The carbon pool balance depends not only on carbon emissions but also on carbon sequestration. Therefore, the carbon source or sink of the composite soil also needs to be further studied.

The texture of soft rock is loose because of the complementary nature of its components: the large amount of montmorillonite is strongly hydrophilic with a high adsorption potential whereas the aeolian sandy soil is leaking water and fertilizer (Sun and Han, 2018). Research on the soft rock and sand compound soil in the early stage showed that the increase of the ratio of soft rock to sand can effectively increase the capillary porosity and decrease the water infiltration coefficient of the aeolian sandy soil (Li et al., 2018a;

Shen et al., 2013; Wang et al., 2017; Zhang et al., 2016). The texture was also improved to a certain extent from sand to sandy loam (Wang et al., 2017). The results of the mechanical test (conditions: the loading confining pressure was set to $50,100,200 \mathrm{kPa}$; the moisture content of the compound soil was $14 \%$; the dry density was $1.6 \mathrm{~g} \mathrm{~cm}^{-3}$ ) for different mixing ratios of soft rock and sand using a dynamic three axis showed that the macroscopic mechanics exhibited a strain-hardening phenomenon with non-linear characteristics (Lei et al., 2018). After adding soft rock, the final water content of the improved soil was significantly higher than that of the aeolian sandy soil, which was beneficial for the maintenance of water 
104 105

106

and fertilizers. The results also indicated that the toxic effect of lead in aeolian sandy soil is effectively and proportionally reduced by the amount of soft rock added (Li et al., 2018a). However, the research only focused on the hydraulic properties, fertility, and the adsorption of the soft rock and aeolian sandy soil during the early stage, lacking research on the carbon source/carbon sink effect of the compound soil. Therefore, the purpose of this study is to (1) clarify the carbon mineralization strength of the compound soil in different proportions of sandstone and sand; (2) understand the microstructure and particle composition of the compound soil; and (3) clarify the carbon fixation effect of different proportions of mixed soil and provide a basis for a sustainable development of the regional ecology. We hypothesized that (1) the addition of different proportions of soft rock can effectively increase the soil organic carbon and mineralized carbon content, acting as a carbon sink when the volume fraction of soft rock is less than 50\%; and (2) with the increase of volume fraction of soft rock, the soil fine particles increase, changing the texture from sand to silt loam.

\section{MATERIALS \& METHODS}

\section{Overview of the test site}

The experimental plot was set up at the Fuping County pilot test base from the Shaanxi provincial land engineering technology research institute. Fuping County $\left(108^{\circ} 57^{\prime}-109^{\circ} 26^{\prime} \mathrm{E}, 34^{\circ} 42^{\prime}-35^{\circ} 06^{\prime} \mathrm{N}\right)$ lies at the transition zone between the Guanzhong plain and the northern Shaanxi plateau that belongs to the gully region of the Weibei Loess Plateau. The terrain is high in the north and low in the south. It slopes from the northwest to the southeast. The elevation in the territory is between $376-1421 \mathrm{~m}$. The area belongs to the continental monsoon warm zone with a semi-arid climate. The annual total radiation is $5187 \mathrm{MJ} \mathrm{m}^{-2}$, the 
125

126

127

128

129

130

131

132

133

134

135

136

137

annual average sunshine hours are about $2389 \mathrm{~h}$ with an annual average temperature of $13{ }^{\circ} \mathrm{C}$, and an annual average precipitation of $527 \mathrm{~mm}$. The interannual variation of precipitation is high, and the annual precipitation coefficient of variation $(\mathrm{CV})$ reaches $21 \%$.

\section{Experiment design}

The field test plot was set to simulate the land condition of the soft rock and sand mixed layer in the Mu Us sandy land. The experimental plot layers were set to a mixture of soft rock and sand at 0-30 cm, and a layer of aeolian sandy soil between $30-70 \mathrm{~cm}$. The soft rock and sand were taken from the Daji Han Village, Xiaoji Han township, Yuyang district, and Yulin city. The minerals in the soft rock mainly include quartz, montmorillonite, feldspar, calcite, illite, kaolinite, and dolomite. The main chemical constituents of soft rock are $\mathrm{SiO}_{2}$ ( $65 \%$ by mass), $\mathrm{Al}_{2} \mathrm{O}_{3}$ (14\% by mass), $\mathrm{Fe}_{2} \mathrm{O}_{3}(12 \%$ by mass $)$ and $\mathrm{CaO}(9 \%$ by mass $)$. The mineral in the sand is mainly quartz $\left(\mathrm{SiO}_{2}\right)$ with a mass fraction of about $82 \%$. The remaining minerals are mainly feldspar ( $10 \%$ by mass), kaolinite ( $4 \%$ by mass), calcite ( $2 \%$ by mass), and amphibole ( $2 \%$ by mass).

The organic carbon content of soft rock and sand are $2.00 \mathrm{~g} \mathrm{~kg}^{-1}$ and $0.63 \mathrm{~g} \mathrm{~kg}^{-1}$, respectively.

The analysis was performed in 2009, and four treatments of soft rock and sand with the different volume ratios of 0:1 (CK), 1:5 (C1), 1:2 (C2), and 1:1 (C3) were selected. Each treatment was repeated 3 times with a total of 12 trial plots and randomly distributed. Each plot area covered $2 \mathrm{~m} \times 2 \mathrm{~m}\left(=4 \mathrm{~m}^{2}\right)$. For uniformity of factors such as illumination and micro-topography, the test plot was arranged from south to north in a "one" shape with a depth of the soil layer of 30-40 cm (Fig. 1), whereas the mixing depth of the soft rock and sand in the test plot was designed in the first $30 \mathrm{~cm}$, simulating the field conditions. The layer between 30-70 cm was completely filled with sand. The experimental field crops were corn (Jincheng 508) 
and wheat (Xiaoyan 22), thus providing two different crops a year, all of which were artificially sown.

147 Different types of fertilizers were tested in the experimental field consisting of urea (including N 46.4\%),

148 diammonium phosphate (containing $\mathrm{N} 16 \%$ and $\mathrm{P}_{2} \mathrm{O}_{5} 44 \%$ ), and potassium sulfate (including $\mathrm{K}_{2} \mathrm{O} 52 \%$ ).

149 The amount of fertilizer applied was $255 \mathrm{~kg} \mathrm{ha}^{-1}(\mathrm{~N}), 180 \mathrm{~kg} \mathrm{ha}^{-1}\left(\mathrm{P}_{2} \mathrm{O}_{5}\right)$ and $90 \mathrm{~kg} \mathrm{ha}^{-1}\left(\mathrm{~K}_{2} \mathrm{O}\right)$. All treatments

were similarly applied. All phosphate and potassium fertilizers were used as base fertilizers, $65 \%$ of

nitrogen fertilizers were used as base fertilizers, and 35\% were combined with the irrigation water to be

applied at the booting stage. Wheat planting time is generally in the middle and late October, whereas the

corn planting time is in the middle and late May. One to two days before sowing, the three fertilizers were

weighed according to the required amount of each plot, evenly spread on the soil surface, and then properly ploughed to mix the fertilizer with the topsoil.

Soil sample collection

After the wheat harvest in May 2018, five uniformly distributed samples from the 0-30 cm soil layer of each plot were collected to form a mixed sample. Animals and plant residues were removed from the collected soil samples. Afterwards, the samples were sieved through a $2 \mathrm{~mm}$ sieve and divided into two parts, one part was placed in a $4{ }^{\circ} \mathrm{C}$ refrigerator for the mineralization incubation test whereas the other part was naturally air-dried, ground and then sieved through a $1 \mathrm{~mm}$ and a $0.149 \mathrm{~mm}$ screen for a subsequent scanning electron microscopy analysis to determine the texture and organic carbon.

Determination method

The mineralization incubation test was carried out by the Alkali Absorption Method (Dai et al., 2017; Ribeiro et 
167

al., 2010; Zibilske 1994 ). For this, the soil placed in the refrigerator at $4^{\circ} \mathrm{C}$ was weighed and $30 \mathrm{~g}$ transferred into a beaker, set to a field water holding capacity of about $60 \%$, and then pre-incubated in the incubator at $25^{\circ} \mathrm{C}$ for 5 days. The purpose was to restore microbial activity and adapt to the current incubation environment. Then the lye and the beaker filled with the soil were transferred into an incubation bottle, sealed, and incubated in the dark. The lye was then analyzed by titration with diluted hydrochloric acid at the days $1,2,3 \mathrm{~d}, 4,5,8,11,14$, $18,22,26$, and 30 , respectively (borax $\left(0.05 \mathrm{~mol} \mathrm{~L}^{-1}\right)$ was used for calibration before each titration). At each titration, $2 \mathrm{~mL}$ of $1 \mathrm{~mol} \mathrm{~L}^{-1} \mathrm{BaCl}_{2}$ solution was added to the soil-filled beaker together with 2 drops of phenolphthalein indicator. Water was added to the soil to a constant weight each time the lye absorption cup was changed.

\author{
Organic carbon was determined by the potassium dichromate-concentrated Sulfuric Acid External
} Heating method (Nelson and Summers, 1996). The texture was measured using a Malvern laser particle size analyzer (MS2000, Malvern, UK). The soil sample after the $1 \mathrm{~mm}$ sieving was cured by epoxy resin, first coarsely then artificially ground, and polished by a sander to make the surface smooth. Thus prepared, a microsample with a diameter of $5 \mathrm{~mm}$ and a height of $3 \mathrm{~mm}$ was obtained. The dried sample was subjected to gold plating, and scanning was performed by a scanning electron microscope (FEI Q45, USA) using a voltage of $25 \mathrm{kV}$ in an "S" type and a magnification of 1000 times.

\title{
Data Processing and Analysis
}

The cumulative amount of soil organic carbon mineralization refers to the total amount of soil $\mathrm{CO}_{2}$ released from the beginning of cultivation to a certain time point. It can be fitted by the first-order kinetic equation using the Origin drawing software 2017, i.e., $\mathrm{C}_{\mathrm{t}}=\mathrm{C}_{0}\left(1-\mathrm{e}^{-\mathrm{kt}}\right)$ (Ribeiro et al., 2010), 
188

189

190

191

192

193

194

195

196

197

198

199

200

201

202

203

204

205

206

207

208

\section{5}

$\mathrm{C}_{\mathrm{t}}=\mathrm{C}_{0}\left(1-\mathrm{e}^{-\mathrm{kt}}\right)$

Where $C_{t}$ is the accumulated mineralization amount of soil organic carbon in $\mathrm{mg} \mathrm{kg}^{-1}$ after time $\mathrm{t}$; $\mathrm{C}_{0}$ is the soil potential mineralized organic carbon in $\mathrm{mg} \mathrm{kg}^{-1} ; \mathrm{k}$ is the constant of organic carbon mineralization rate, $\mathrm{d}^{-1} ; \mathrm{t}$ is the number of days of cultivation, and $\mathrm{d}$ the half-turn period $\mathrm{T}_{1 / 2}=\ln 2 / \mathrm{k}$.

Texture data was classified using the TriangleVB software. All data was sorted and graphed using EXCEL 2019, and the analysis of variance and multiple comparisons were performed using SPSS 19.0.

\section{RESULTS}

\section{Compound soil organic carbon}

The organic carbon content of aeolian sandy soil can be significantly improved by adding different proportions of soft rock (Fig. 2). The organic carbon content in the CK treatment was $2.02 \mathrm{~g} \mathrm{~kg}^{-1}$. The organic carbon content in the $\mathrm{C} 1, \mathrm{C} 2$, and $\mathrm{C} 3$ treatments was significantly increased compared to that of the CK treatment $(\mathrm{P}<0.05)$ with increases of $110 \%, 77 \%$ and $119 \%$, respectively. With the increase of the proportion of soft rock, the soil organic carbon first increased, then decreased, to continue to increase again.

The organic carbon content in the $\mathrm{C} 1$ treatment was $4.24 \mathrm{~g} \mathrm{~kg}^{-1}$, and the organic carbon content of $\mathrm{C} 2$ and C3 treatment decreased and increased by $16 \%$ and $4 \%$, respectively. Though there was an increase by $24 \%$ in the $\mathrm{C} 3$ treatment compared to the $\mathrm{C} 2$ treatment, there was no significant difference $(\mathrm{P}>0.05)$.

\section{Compound soil organic carbon mineralization rate}

The mineralization rate of organic carbon in soils with different mixing ratios of soft rock and sand showed a logarithmic, dynamic downward trend with the cultivation time with a relation of $y=a+b \ln (x)(P<$ 
209

210

211

212

213

214

215

216

217

218

219

220

221

222

223

224

225

226

227

228

229

0.01) (Fig. 3, Table 1). The logarithm function does not introduction of mineralization potential and other

parameters, which reflects the pure digital variation law, indicating that the data trend is better. The mineralization rates of organic carbon in the $\mathrm{CK}$ and $\mathrm{C} 3$ treatments reached their peaks compared to day 1 on day 3 of incubation with $49.6 \mathrm{mg} \mathrm{kg}^{-1} \mathrm{~d}^{-1}(76 \%)$ and $66.1 \mathrm{mg} \mathrm{kg}^{-1} \mathrm{~d}^{-1}(37 \%)$, respectively. The mineralization rate of organic carbon decreased rapidly after day 3 slowing down its decline after day 11.

The organic carbon mineralization rate at 30 days of cultivation was $3.4 \mathrm{mg} \mathrm{kg}^{-1} \mathrm{~d}^{-1}(\mathrm{CK})$ and $13.5 \mathrm{mg} \mathrm{kg}^{-}$

${ }^{1} \mathrm{~d}^{-1}(\mathrm{C} 3)$, respectively, which indicates a decrease by $93 \%$ and $80 \%$ compared to day 3 . However, the organic carbon mineralization rate in the $\mathrm{C} 1$ and $\mathrm{C} 2$ treatment exhibited its maximum on the first day of incubation with $58.7 \mathrm{mg} \mathrm{kg}^{-1} \mathrm{~d}^{-1}$ and $43.5 \mathrm{mg} \mathrm{kg}^{-1} \mathrm{~d}^{-1}$, respectively. The mineralization rate in the $\mathrm{C} 1$ and $\mathrm{C}$ 2 treatments rapidly declined until day 11 , after that this decline slowed down. The mineralization rate on the day 30 was $83 \%$ and $81.68 \%$ lower than that of the first day, respectively. Taken together, the average mineralization rate in the $\mathrm{C} 3$ treatment was the highest in all compound ratio treatments, followed by the $\mathrm{C} 1$ and the $\mathrm{C} 2$ treatment, whereas the $\mathrm{CK}$ treatment exhibited the lowest mineralization rate. The mineralization rate of all treatments can be divided into two stages: namely a rapid decline (1-11 days) and steady decline (11-30 days). In general, the $\mathrm{CO}_{2}$ production rate changed greatly during the rapid decline phase, whereas the mineralization rate between all treatments was consistent during the steady decline phase.

\section{Cumulative mineralization of compound soil organic carbon}

The relationship between the cumulative mineralization of organic carbon and the incubation time in different proportions of soft rock and sand demonstrated a logarithmic function relationship $y=a+b \ln (x)$

Peer] reviewing PDF | (2019:05:37951:3:0:NEW 16 Aug 2019) 
$230(\mathrm{P}<0.01)$ (Fig. 4, Table 1). The results showed that the organic carbon accumulation mineralization

231 decreased gradually with the incubation time, which indicates that the $\mathrm{CO}_{2}$ release rate decreased. During

232 the whole incubation period, the cumulative mineralization of organic carbon was significantly the highest

233 in the $\mathrm{C} 3$ treatment, followed by the $\mathrm{C} 1$ and $\mathrm{C} 2$ treatments, whereas the $\mathrm{CK}$ treatment had the lowest

234 mineralization accumulation $(\mathrm{F}=26.54, \mathrm{P}<0.01)$. After incubation for 30 days, the cumulative

235 mineralization of organic carbon in the CK treatment was $274 \mathrm{mg} \mathrm{kg}^{-1}$. The cumulative mineralization of

236 organic carbon treated by $\mathrm{C} 1, \mathrm{C} 2$ and $\mathrm{C} 3$ increased significantly by $88 \%, 59 \%$, and $193 \%$ as compared to

237 CK, respectively (Table 2). There was no significant difference in the cumulative mineralization of organic

carbon between the $\mathrm{C} 1$ and $\mathrm{C} 2$ treatments. Compared to the $\mathrm{C} 1$ and $\mathrm{C} 2$ treatment, the cumulative mineralization of organic carbon in C3 treatment was significantly increased by $55 \%$ and $84 \%$, respectively.

\section{Cumulative mineralization rate of organic carbon in compound soil}

The cumulative mineralization rate of soil organic carbon in the different compound ratios of soft rock and

sand can reflect the strength of the carbon fixation capacity in the new compound soil. The higher the ratio,

the weaker the carbon sequestration capacity of the soil, and vice versa. Fig. 5 shows that the cumulative mineralization rate of soil organic carbon in the three treatments of $\mathrm{CK}, \mathrm{C} 1$, and $\mathrm{C} 2$ did not reach a significant difference after 30 days of incubation $(\mathrm{P}>0.05)$. In our analysis, $\mathrm{C} 1$ exhibited the lowest cumulative mineralization rate in the three treatments. The cumulative mineralization rate of organic carbon in the $\mathrm{C} 3$ treatment was $18 \%$, which was significantly increased by $4.6,6.0$ and 6.0 percentage points as compared to $\mathrm{CK}, \mathrm{C} 1$ and $\mathrm{C} 2$, respectively. Compared to the $\mathrm{C} 1$ treatment, the cumulative mineralization 
251

252

253

254

255

256

257

258

259

260

261

262

263

264

265

266

267

268

269

270

271

respectively.

\section{Fitting parameters of organic carbon mineralization in compound soil}

There were significant differences between the parameters of the kinetic equations of organic carbon mineralization in the treatments with different proportions of soft rock and sand. Indeed, the first-order kinetic equation $\mathrm{C}_{\mathrm{t}}=\mathrm{C}_{0}\left(1-\mathrm{e}^{-\mathrm{kt}}\right)$ was used for parameter fitting $(\mathrm{P}<0.01)$ and introduced two parameters of mineralization rate constant and potential mineralizable carbon. The potential mineralizable organic carbon $\left(\mathrm{C}_{0}\right)$ content of the $\mathrm{CK}$ treatment was $257 \mathrm{mg} \mathrm{kg}^{-1}$, and the $\mathrm{C}_{0}$ values in $\mathrm{C} 1, \mathrm{C} 2$ and $\mathrm{C} 3$ treatment were significantly increased by $104 \%, 88 \%$, and $264 \%$, respectively $(\mathrm{P}<0.05)$. There was no significant difference between the $\mathrm{C} 1$ and $\mathrm{C} 2$ treatments (Table 2), whereas the $\mathrm{C} 3$ treatment exhibited significantly increased $\mathrm{C}_{0}$ values with $78 \%$ and $93 \%$ compared to the $\mathrm{C} 1$ and $\mathrm{C} 2$ treatments. The $\mathrm{k}$-values (the organic carbon mineralization rate constant) of the $\mathrm{C} 1, \mathrm{C} 2$, and $\mathrm{C} 3$ treatments were lower than those of the $\mathrm{CK}$ treatment though not significantly. The trend of $\mathrm{T}_{1 / 2}$ (half-turn period) was opposite to that of the k-values, indicating that the addition of different proportions of soft rock reduced the mineralization rate constant of organic carbon and increased the retention time of organic carbon in the soil. The $\mathrm{C}_{0} / \mathrm{SOC}$ (SOC: soil organic carbon) of the $\mathrm{CK}$ treatment was $13 \%$. Taken together, the $\mathrm{C} 1, \mathrm{C} 2$, and $\mathrm{CK}$ treatments were not significantly different to each other whereas the $\mathrm{C} 3$ treatment was significantly increased by $8 \%$ compared to the CK treatment.

\section{Compound soil microstructure}

The microstructure of the compound soil provides us some information about the corresponding soil 
272 structure. Using the scanning electron microscope (SEM) we observed irregular shapes of sand grains.

273 Though the degree of grinding was high, there were no sharp edges and angles in the CK treatment (Fig. 6-

274 a). With the increase of the volume fraction of the soft rock $(\mathrm{C} 1, \mathrm{C} 2, \mathrm{C} 3)$ (Fig. 6-b, c, and d), the overall

275 structure of the composite soil showed no obvious change but the filling of fine particles increased

276 gradually. As the volume fraction of small particles gradually increased, the distance between the small and

277 large particles increased more than the one between the large particles. When the content of soft rock reached $50 \%(\mathrm{C} 3$, Fig. $6-\mathrm{d})$, due to the increase of the specific surface area of the small particles, the large particles were not enough to support the soil structure, which entailed a collapse of the soil mass.

\section{Compound soil mechanical composition}

In the CK treatment, the content of sand was $87 \%$. With the increase of the proportion of soft rock, the sand content gradually decreased, which was for the $\mathrm{C} 1, \mathrm{C} 2$, and $\mathrm{C} 3$ treatment as compared to the $\mathrm{CK}$ treatment 33, 42 and 46 percentage points, respectively $(\mathrm{P}<0.05)$. The silt content increased gradually with the increase of soft rock, which was for the $\mathrm{C} 1, \mathrm{C} 2$, and $\mathrm{C} 3$ treatment an increase of 29, 35, and 39 percentage points, respectively $(\mathrm{P}<0.05)$. The clay content of the $\mathrm{CK}$ treatment was $2.3 \%$. With the increase of volume fraction of soft rock, the clay content in the $\mathrm{C} 1, \mathrm{C} 2$ and $\mathrm{C} 3$ treatments increased by 4.5, 7.0 and 7.2 percentage points, respectively, as compared to the $\mathrm{CK}$ treatment $(\mathrm{P}<0.05)$. Thus, the increase of the clay component was smaller than that of silt. There were no significant differences between the three $\mathrm{C} 1, \mathrm{C} 2$, and $\mathrm{C} 3$ treatments. Taken together, with the increased volume fraction of soft rock, the texture of compound soil gradually changed from sandy soil to sandy loam, loam, and silty loam (Fig. 7). 
293

294

295

296

297

298

299

300

301

302

303

304

305

306

307

308

309

310

311

312

313

\section{DISCUSSION}

Soil organic carbon mineralization is an important biochemical process in soil, which is directly related to the release and supply of soil nutrient elements, $\mathrm{CO}_{2}$ gas emissions, and soil quality maintenance (Ross et $a l ., 1999)$. In our analysis, we used four treatments, with the different volume of soft rock to sand ratios of 0:1 (CK), 1:5 (C1), 1:2 (C2), and 1:1 (C3), respectively. During the whole incubation period, the CK and C3 treatment demonstrated the same mineralization reaction characteristics, reaching a peak on the 3rd day, followed first by a rapid and subsequently a slow decline (Fig. 3). This can be explained in that the soil microenvironment was still at the beginning of the reaction and that the compound soil organic carbon in the initial stage of mineralization was mostly in the form of complex compounds. Thus, during this stage only a few small molecular compounds were easily decomposed. Microorganism need to simplify the complex compound before it can be absorbed and utilized, which is indicated by a rapid rising phase of the respiratory rate at the initial stage $(\mathrm{Li}, 2000$; Alvarez et al., 1998). The reaction characteristics of the $\mathrm{C} 1$ and $\mathrm{C} 2$ treatment were similar as the trend of decrease was observed throughout the complete incubation period. All the treatments can be divided into two stages: a rapid decline on days 1 to 11 and a steady decline on days 11 to 30 . The cumulative mineralization on day 11 reached $55 \%-74 \%$ of the total mineralization (Fig. 4), which was consistent with the study of Zhang et al. (2011). During the early mineralization stage, the organic matter mainly decomposed by soil microbes is derived from animal and plant residues and their secretions (Li et al., 2010). Thus, many active organic substances such as sugars and proteins were easily decomposed in the soil at this initial stage providing abundant carbon sources and nutrients for soil microorganisms and promoting microbial activity. With the prolongation of cultivation time, the active organic components, which were easily to decompose within the soil, were gradually used 
314 up by the microorganisms and the remaining components such as lignin and cellulose are more difficult to

315 be access by the microorganisms (Kögel-Knabner et al., 2010; Yang et al., 2007). Therefore, the

316 mineralization rate showed a trend from fast to slow which mirrors the decomposition rate, whereas the

317 cumulative mineralization showed a cumulative trend of a gradual decrease in release intensity

318 (Franzluebbers et al., 2001; Li et al., 2018b). Obviously, the amount of soil nutrient plays an important role

319 in the organic carbon mineralization process. Kemmitt et al. (2008) studied the mineralization process of

some microorganisms and found that after fumigation with chloroform, which reduced the number of

microorganisms by $90 \%$, the mineralization rate of organic carbon among all treatments had no significant

difference compared to the control treatment. Thus, the mineralization of soil organic matter was limited

by a non-biological process that converts the substrate into microbial utilization (Kemmitt et al., 2008). At

this stage, microorganisms only play a minor role as the available organic materials become a limiting

factor. Based on a hypothesis, Kemmitt et al. (2008) divided the process of humified soil organic matter

mineralization into two steps. The first step is a-biological and independent of any microbial processes. The

possible mechanisms include chemical oxidation or hydrolysis, diffusion from inaccessible soil pores or aggregates, desorption from the solid phase, and the action of extracellular stabilized enzymes. The second step is the mineralization by the soil microorganisms of this small, now biologically available, trickle of substrate derived from humified soil organic matter. This trickle of substrate is equally available to both the small developing recolonizing population in the fumigated soil and the larger population in the nonfumigated soil. Hypothetically, if the soil microorganisms acted directly on solid soil, this would likely 
335

336

337

338

339

340

341

342

microbial use, and the second step is to transfer these substances via diffusion to other microbes. Kemmitt

et al. (2008) described the non-biological dominated mineralization process as similar to that of microorganisms acting directly on solid soil. Sollins et al. (1996) also believe that the mineralization process and unstable processes of soil organic matter cannot be enhanced by increasing the activity of microorganisms. The mineralization process in their study may be a comparable process as that described by Kemmitt et al. (2008) for the end of the first stage and the beginning of the second stage. Taken together, a special research is needed about the role of microorganisms during the mineralization process.

Despite the same, comparable incubation conditions within our experiments, there were significant differences in soil organic carbon accumulation mineralization $\left(\mathrm{C}_{t}\right)$ with different compounding ratios, which was $\mathrm{C} 3>\mathrm{C} 1>\mathrm{C} 2>\mathrm{CK}$. This indicates a consistent trend with the content of organic carbon (Fig. 2).

The low content of soil organic carbon in the CK treatment affects the mineralization rate of soil organic carbon, which results in a relatively small cumulative release of $\mathrm{CO}_{2}$. The aeolian sandy soil has a higher sand content, larger permeability coefficient, and a serious water and fertilizer leakage. On the other hand, there are many small particles in the soft rock, which are hydrophilic and adsorbent. In our experiment, mixing soft rock and aeolian sandy soil in a certain proportion promoted the increase of organic carbon content and mineralized amount. The results of this study indicated that the soil clay and silt content increased with adding more soft rock. When the content of soft rock was $17 \%$ ( $\mathrm{C} 1$ treatment), the soil texture was then a sandy loam (Fig. 7), and the cumulative mineralization rate of soil organic carbon was the lowest at the beginning (Fig. 5). When the content of soft rock was 33\% (C2 treatment), the soil texture was loam, and the soil organic carbon accumulation mineralization rate was similar to the $\mathrm{C} 1$ treatment, indicating that a compound ratio of soft rock and sand between 1:5 to 1:2 can promote the accumulation 
356

357

358

359

360

361

362

363

364

365

366

367

368

369

370

371

372

373

374

375

376

of soil organic carbon.

From the scanning electron microscope image (Fig. 6-a) it can be seen that the soil particles in the CK treatment (aeolian sandy soil) do not adhere to each other, the spacing between the soil particles was large, and the pores developed, mainly non-capillary pores. Therefore, the aeolian sandy soil has a good ventilation effect but it has difficulties in effectively maintaining the moisture, so it will leak water and fertilizer, which was not conducive for plant growth. The soil composition of CK treatment was single and the texture uniform, most of which were sand grains. After the addition of soft rock in different proportions, the soil texture changed from sand to sandy loam to loam to silt loam (Fig. 7). Fig. 6-b shows that some of the single particles have a higher degree of roundness, and some soil particles with rough surface and mutual adhesion have agglomerate characteristics, which mainly derive from the soft rock. Compound soil began to appear on the surface of the clay, which was conducive to the benign transformation of the compound soil structure (Fig. 6-b, c, d). The reasons for the formation of the structure can be summarized in three types: (1) When the soft rock was mixed with sand, the silt and clay particles in the soft rock came in contact with the aeolian sand, whereas the silt and clay particles were gradually adsorbed around the sand; (2) In the process of artificial improvement, irrigation and organic matter increased the cementing material in the compound soil, and the cementation promoted the formation of soil aggregates; (3) Various external stresses such as crop root activity and animal activities promote the formation of soil aggregate structure. It can be concluded that the addition of soft rock was improving the loose structure of the sandy land, promoting the agglomeration and cementation of soil, and thus improving the aeration and permeability of soil. However, adding more soft rock does not consequently lead to better results. When the soft rock content reached $50 \%$ (C3 treatment), the large particles were not enough to support the soil structure, entailing the collapse of 
377 the soil (Fig. 6-d). At this composition, the soil texture was a silt loam, and the cumulative mineralization

378 rate was the highest of all treatments. Thus, the change of soil structure plays an important role in organic

379 carbon mineralization. The change in mechanical properties of the soil caused by the change of soil structure

380 remains to be further studied.

381 In addition to soil structure, texture, and nutrients, soil organic carbon mineralization also has an

impact on water content. In our study, the organic carbon retention effect in the $\mathrm{C} 2$ treatment was the best.

The high moisture content may have little effect on the amplitude variation, similar to the variation law

revealed by Jia et al. (2017), who believed that the cumulative mineralization amount and mineralization

rate of organic carbon increase with the increase of soil moisture content but then subsequently gradually

decreases. In our previously reported experiments (Sun and Han, 2018), we showed that the C2-like treated

compound soil had the highest water content and the C1-like treatment had the greatest impact on soil water

storage. According to Cooper et al. (2011), temperature was the primary factor driving soil organic carbon

mineralization. The mineralization rate and cumulative mineralization amount of soil organic carbon

increased with the increase of cultivation temperature, though the most significant effect of the temperature

observed was outside the normal temperature range. Among the different agricultural measures, tillage

systems also change the stability of soil aggregates, thereby affecting the loss of carbon stocks. Stable

macroaggregates in cultivated soil can retain more carbon than microaggregates but macroaggregates were

more easily mineralized than microaggregates (Goh, 2004). The soil also contains many different metal 
398

399

400

401

402

403

404

405

406

407

408

409

410

411

412

413

414

microorganic decomposition of organic matter. Taken together, soil nutrients, texture, water content, temperature, tillage measures, metal ions, and many other factors cause differences in the soil organic carbon mineralization. Future research should therefore focus on the later stages of the factors not involved. Soil potentially mineralizable organic carbon $\left(\mathrm{C}_{0}\right)$, also known as biodegradable carbon, is the total amount of organic matter that can be decomposed under the action of microorganisms (Guo et al., 2019).

The $\mathrm{C}_{0}$ values in this study were consistent with the changes in $\mathrm{C}_{\mathrm{t}}$ value, and the specific performance was $\mathrm{C} 3>\mathrm{C} 1>\mathrm{C} 2>\mathrm{CK}$. The reason was that with the increase in soft rock content, the non-capillary space between the sand grains was filled by the soft rock, increasing the capillary pressure and promoting the formation of the soil aggregate structure. The soft rock was also rich in carbonate and other mineral components. As the soft rock volume fraction increased, the cementation force of the compound soil also increased significantly. Because the organic carbon content of the compound soil is significantly higher than that in the CK treatment, the activity of plant roots and animals in the compound soil also promotes the fusion of soft rock and sand (Han et al., 2012). Li et al. (2010) studied the soil organic carbon mineralization in the Loess Plateau. They found that that the organic carbon mineralization rate constant $\mathrm{k}$ was neither affected by soil nutrient nor by $\mathrm{pH}$, but it was influenced by particle composition. The results in our study showed that there was no significant difference in the k-value between the $\mathrm{C} 1, \mathrm{C} 2$, and $\mathrm{C} 3$ treatments, though they were significantly lower than in the CK treatment. Also, the changes in $T_{1 / 2}$ and $k$ values were opposite. One explanation might be that the long-term application of chemical fertilizers in this experiment increased the inorganic nitrogen content, such as soil nitrate nitrogen and ammonium nitrogen, which then reacts with other compounds such as lignin or phenol present in the soil. This reaction lowers the decomposition properties changed of organic carbon had (Jenkinson et al., 1985; Liu et al., 2017). Other studies showed 
419 that the increased amount of soft rock can promote the formation of aggregates in the compound soil, so

420 that some organic carbon particles are encapsulated by the aggregates thus avoiding degradation and

421 increasing the retention time of organic carbon in the soil (Pulleman and Marinissen, 2004; Chevallier et

422 al., 2004). The $\mathrm{C}_{0} / \mathrm{SOC}$ value can reflect the solid storage capacity of the compound soil organic carbon:

423 the larger the ratio, the stronger the soil organic carbon mineralization ability, and vice versa. The results

424 of this study indicated that the $\mathrm{C}_{0} / \mathrm{SOC}$ values in all treatments were $\mathrm{C} 3>\mathrm{CK}>\mathrm{C} 2>\mathrm{C} 1$, with no significant

425 difference between $\mathrm{C} 1$ and $\mathrm{C} 2$, which was consistent with the trend observed in the soil organic carbon

426 accumulation mineralization rate.

427

\section{CONCLUSIONS}

429 The soil organic carbon content can be significantly increased by the different compound ratios of soft rock

and sand. With an increased soft rock content, the content of soil sand gradually decreased, while the content

of clay and silt gradually increased, with the largest increase in silt. The soil texture changed from sand to

sandy loam, then to loam and silty loam. The results of the scanning electron microscopy showed that the

specific surface area between large particles and small particles increased with the increase of volume

fraction between soft rock and sand. Interestingly, when the soft rock volume fraction was $50 \%$, the soil

structure collapsed. The $\mathrm{C} 1$ and $\mathrm{C} 2$ treatments had the highest mineralization rate on the first day of

incubation, whereas the $\mathrm{CK}$ and $\mathrm{C} 3$ treatment reached their maximum on the third day of cultivation. The

whole cultivation process can be divided into a rapid decline between days 1 to 11 and a slow decline 
440

441

442

443

444

445

446

447

448

449

450

451

452

453

454

455

456

457

458

459

460

and $\mathrm{C} 2$ treatments was the lowest in all treatments, and $\mathrm{C}_{0} / \mathrm{SOC}$ was consistent with its variation rule. The

organic carbon turnover rate was significantly decreased and the retention time in soil was increased with the addition of soft rock. Here, the $\mathrm{C} 1$ and $\mathrm{C} 2$ treatment showed the best effect. The accumulation of compound soil organic carbon can be significantly increased when the ratio of soft rock to sand was 1:5 to

1:1. A comprehensive mineralization index and scanning electron microscopy analysis indicated that the compounding ratio of 1:5 to 1:2 can be used as an important basis for farmland carbon sequestration and soil remediation measures.

\section{ACKNOWLEDGEMENTS}

We thank professor Jichang Han for providing the soil resources. Also, thanks to the Shaanxi Provincial Land Engineering Construction Group for their strong support of this project.

\section{REFERENCES}

Alvarez CR, Alvarez R, Grigera MS, Lavado RS. 1998. Associations between organic matter fractions and the active soil microbial biomass. Soil Biology \& Biochemistry 30:767-773.

Chevallier T, Blanchart E, Albrecht A, Feller C. 2004. The physical protection of soil organic carbon in aggregates: a mechanism of carbon storage in a vertisol under pasture and market gardening (Martinique, West Indies). Agriincubation, Ecosystems \& Environment 103:375-387.

Cooper JM, Burton D, Daniell TJ, Griffith BS, Zebarth BJ. 2011. Carbon mineralization kinetics and soil biological characteristics as influenced by manure addition in soil incubated at a range of temperatures. European Journal of Soil Biology 47:392-399.

Peer] reviewing PDF | (2019:05:37951:3:0:NEW 16 Aug 2019) 
461

462

463

464

465

466

467

468

469

470

471

472

473

474

475

476

477

478

479

480

481

Dai XQ, Wang HM, Fu XL. 2017. Soil microbial community composition and its role in carbon mineralization in long-term fertilization paddy soils. Science of the Total Environment 580:556-563.

Feng Q, Liu W, Zhang YW, Si JH, Su YH, Chang ZQ, Xi HY. 2006. Effect of climatic changes and human activity on soil carbon in desertified regions of China. Tellus B: Chemical and Physical Meteorology 58:117-128.

Franzluebbers AJ, Haney RL, Honeycutt CW, Arshad MA, Schomberg HH, Hons FM. 2001. Climatic influences on active fractions of soil organic matter. Soil Biology \& Biochemistry 33:11031111.

Goh MK. 2004. Carbon sequestration and stabilization in soils: implications for soil productivity and climate change. Soil Science and Plant Nutrition 50:467-476.

Guo Z, Wang XL, Duan JJ, Jiao KQ, Sun SS, Duan YH. 2018. Long-term fertilization and mineralization of soil organic carbon in paddy soil from yellow earth. Acta Pedologica Sinica 55:225-236.

Guo Z, Han JC, Li J, Xu Y, Wang XL. 2019. Effects of long-term fertilization on soil organic carbon mineralization and microbial community structure. PLoS One 14:e0211163.

Han JC, Liu YS, Luo LT. 2012. Research on the core technology of remixing soil by soft rock and sand Mu Us sand land region. Chinese Land Science 26:87-94.

Jenkinson DS, Fox RH, Rayner JH. 1985. Interactions between fertilizer nitrogen and soil nitrogen the so-called “priming” effect. Journal of Soil Science Banner 36:425-444.

Jia JX, Yu YZ, Zhang J, Xu JM, Zhang YL, Zhao Y, Hong JP. 2017. Effect of soil moisture on mineralization of soil carbonin calcareous soils in the semi-arid regions of China. Journal of 
Irrigation and Drainage 36:62-68.

\section{Kemmitt SJ, Lanyon CV, Waite IS, Wen Q, Addiscott TM, Bird NRA, O'Donnell AG, Brookes PC.} 2008. Mineralization of native soil organic matter is not regulated by the size, activity or composition of the soil microbial biomass-a new perspective. Soil Biology \& Biochemistry 40:61-73.

\section{Kögel-Knabner I, Amelung W, Cao ZH, Fiedler S, Frenzel P, Jahn R, Karsten K, Kölbl A, Schlotor} M. 2010. Biogeochemistry of paddy soils. Geoderma 157:1-14.

Lal R. 2004. Soil carbon sequestration impacts on global climate change and food security. Science 304:1623-1627.

Lei GY, Wang HY, Xie X. 2018. Study on mechanical properties of the compound soil of feldspathic sandstone and sand based on micro level. West Development (Land Development Engineering Research) 3:52-57.

Li JB, Li J, Wang Z. 2018a. Study on the migration and migration of heavy metals in different proportions of strontium soft rock and sand complex soil. West Development (Land Development Engineering Research) 3:35-40.

Li J, Wu X, Gebremikael MT, Wu H, Cai D, Wang B. 2018b. Response of soil organic carbon fractions, microbial community composition and carbon mineralization to high-input fertilizer practices under an intensive agricultural system. PLoS One 13:e195144.

Li CS. 2000. Modeling trace gas emissions from agricultural ecosystems. Nutrient Cycling in Agroecosystems 58:259-276.

Li SJ, Qiu LP, Zhang XC. 2010. Mineralization of soil organic carbon and its relations with soil physical and chemical properties on the Loess Plateau. Acta Ecology Sinica 30:1217-1226. 
503

504

505

506

507

508

509

510

511

512

513

514

515

516

517

518

519

520

521

522

523

Liu G, Du Q, Li J. 2017. Interactive effects of nitrate-ammonium ratios and temperatures on growth, photosynthesis, and nitrogen metabolism of tomato seedlings. Scientia Horticultural 214:41-50.

Nelson DW, Sommers LE. 1996. Total carbon, organic carbon and organic matter. In: Sparks DL, Page AL, Helmke PA, Loeppert RH, Soltanpour PN, Tabatabai MA, Jh CT, Sumner ME, editors. Methods of soil analysis, Part 3, chemical methods. Soil Science Society of America, Madison, Wisconsin, USA, pp. 961-1010.

Pan GX, Smith P, Pan WN. 2009. The role of soil organic matter in maintaining the productivity and yield stability of cereals in China. Agriincubation Ecosystems \& Environment 129:344-348.

Pulleman MM, Marinissen JCY. 2004. Physical protection of mineralizable C in aggregates from longterm pasture and arable soil. Geoderma 120:273-282.

Rasmussen C, Southard RJ, Horwath WR. 2006. Mineral control of organic carbon mineralization in a range of temperate conifer forest soils. Global Change Biology 12:834-847.

Ribeiro HM, Fangueiro D, Alves F, Vasconcelos E, Coutinho J, Bol R, Cabral F. 2010. Carbonmineralization kinetics in an organically managed cambic arenosol amended with organic fertilizers. Journal of Plant Nutrition and Soil Science 173:39-45.

Ross DJ, Tate KR, Scott NA, Feltham CW. 1999. Land-use change: effects on soil carbon, nitrogen and phosphorus pools and fluxes in three adjacent ecosystems. Soil Biology \& Biochemistry 31:803-813.

Schmitz OJ, Buchkowski RW, Smith JR, Telthorst M, Rosenblatt AE. 2017. Predator community composition is linked to soil carbon retention across a human land use gradient. Ecology 98:12561265.

Shen F, Xu Y, Chen JP, Zuo CQ. 2013. Sensitivity analysis of soft rock mechanics parameters on 
524

525

526

527

528

529

530

531

532

533

534

535

536

537

538

539

540

541

542

543

544

tunnel mechanics characteristic. Applied Mechanics and Materials 368-370:1756-1761.

She XY, Wei XR, Wei YC, Ma TE, Xu JJ, Zhang XC. 2015. Effects of soft rock modified sandy soil on $\mathrm{NH}_{4}{ }^{+}-\mathrm{N}$ adsorption characteristics. Transactions of the Chinese Society for Agricultural Machinery 46:165-173.

Sollins P, Homann P, Caldwell BA. 1996. Stabilization and destabilization of soil organic matter: mechanisms and controls. Geoderma 74:65-105.

Stumpf F, Keller A, Schmidt K, Mayr A, Gubler A, Schaepman M. 2018. Spatio-temporal land use dynamics and soil organic carbon in swiss agroecosystems. Agriincubation, Ecosystems \& Environment 258:129-142.

Sun Z, Han J. 2018. Effect of soft rock amendment on soil hydraulic parameters and crop performance in Mu Us sandy land, China. Field Crops Research 222:85-93.

Tommaso C, Emanuele B, Guido P, Lucia P, Vincenza CM, Riccardo V. 2018. Soil organic carbon pool's contribution to climate change mitigation on marginal land of a Mediterranean montane area in Italy. Journal of Environmental Management 218:593-601.

Wang YC, Wu YH, Kou Q, Min DA, Chang YZ, Zhang RJ. 2007. Delineation of soft rock distribution and classification of type zones. Soil and Water Conservation in China 5:14-18.

Wang M. 2016. Effects of PP_(333) on photosynthesis and physiological characteristics of Yangchai under compound soil environment. Inner Mongolia Agricultural University.

Wang HY, Han JC, Tong W, Cheng J, Zhang HO. 2017. Analysis of water and nitrogen use efficiency for maize (Zea mays l.) grown on soft rock and sand compound soil. Journal of the Science of Food and Agriincubation 97:2553. 
545

546

547

548

549

550

551

552

553

554

555

556

557

558

559

560

561

Yang L, Pan J, Shao Y, Chen JM, Ju WM, Shi X, Yuan X. 2007. Soil organic carbon decomposition and carbon pools in temperate and sub-tropical forests in China. Journal of Environmental Management 85:690-695.

Zhang P, Li H, Jia ZK, Wang W, Lu WT, Zhang H. 2011. Effects of straw returning on soil organic carbon and carbon mineralization in semi-arid areas of southern Ningxia, China. Journal of AgroEnvironment Science 30:2518-2525.

Zhang H, Tang J, Liang S, Li Z, Wang J, Wang S. 2018. Early thawing after snow removal and no straw mulching accelerates organic carbon cycling in a paddy soil in northeast China. Journal of Environmental Management 209:336-345.

Zhang BJ, Huang B, Mei C, Fu XD, Luo G, Yang ZJ. 2016. Dynamic behaviours of a single soft rocksocketed shaft subjected to axial cyclic loading. Advances in Materials Science and Engineering 2016:1-9.

Zhou XB, Zhang YM. 2009. Research progress on ecological effects of nitrogen deposition in arid and semi-arid areas. Journal of Ecology 29:3835-3845.

Zibilske LM. 1994. Carbon Mineralization. In: Weaver RW, Angle JS, Bottomly P, editors. Methods of Soil Analysis, Part 2, Microbiological and Biochemical Properties. Soil Science of America Inc., Madison, Wisconsin, USA, pp. 835-863. 


\section{Table 1 (on next page)}

Table 1 Regression equation of soil organic carbon mineralization rate and cumulative mineralization under different compounding ratios. 
1 Table 1 Regression equation of soil organic carbon mineralization rate and cumulative

2 mineralization under different compounding ratios.

\begin{tabular}{|c|c|c|c|}
\hline Index & Treatment & Regression equation & $\mathrm{r}$ \\
\hline \multirow{5}{*}{ Mineralization rat } & $\mathrm{CK}$ & $\mathrm{y}_{1}=-12.10 \ln (\mathrm{x})+41.28$ & $0.7933 * *$ \\
\hline & $\mathrm{C} 1$ & $\mathrm{y}_{1}=-14.56 \ln (\mathrm{x})+54.378$ & $0.9298^{* *}$ \\
\hline & & & \\
\hline & $\mathrm{C} 2$ & $\mathrm{y}_{1}=-10.06 \ln (\mathrm{x})+40.408$ & $0.9595 * *$ \\
\hline & $\mathrm{C} 3$ & $\mathrm{y}_{1}=-14.40 \ln (\mathrm{x})+64.713$ & $0.8679 * *$ \\
\hline & $\mathrm{CK}$ & $\mathrm{y}_{2}=71.928 \ln (\mathrm{x})+30.107$ & $0.9935^{* *}$ \\
\hline Cumulative & $\mathrm{C} 1$ & $\mathrm{y}_{2}=132.40 \ln (\mathrm{x})+9.2284$ & $0.9752 * *$ \\
\hline \multirow[t]{2}{*}{ mineralization } & $\mathrm{C} 2$ & $\mathrm{y}_{2}=121.50 \ln (\mathrm{x})-14.676$ & $0.9757 * *$ \\
\hline & $\mathrm{C} 3$ & $\mathrm{y}_{2}=234.98 \ln (\mathrm{x})-60.922$ & $0.9795^{* *}$ \\
\hline
\end{tabular}

3 Notes: CK: the volume ratio of soft rock to sand is $0: 1 ; \mathrm{C} 1$ : the volume ratio of soft rock to sand is 1:5;

$4 \mathrm{C} 2$ : the volume ratio of soft rock to sand is $1: 2 ; \mathrm{C} 3$ : the volume ratio of soft rock to sand is $1: 1 . \mathrm{y}_{1}: \mathrm{CO}_{2}$

5 production rate, $\mathrm{mg} \mathrm{kg}^{-1} \mathrm{~d}^{-1} ; \mathrm{y}_{2}: \mathrm{CO}_{2}$ accumulative release amount, $\mathrm{mg} \mathrm{kg}^{-1} ; \mathrm{x}$ : incubation day, $\mathrm{d} ;{ }^{* *}$ means

6 significant correlation at 0.01 level.

7 
Table 2 (on next page)

Table 2 Cumulative mineralization of SOC after the 30 days of incubation and parameters of its kinetic equations. 
1 Table 2 Cumulative mineralization of SOC after the 30 days of incubation and parameters of its

2 kinetic equations.

\begin{tabular}{ccccccc}
\hline Treatment & $\mathrm{C}_{\mathrm{t}}\left(\mathrm{mg} \mathrm{kg}^{-1}\right)$ & $\mathrm{C}_{0}\left(\mathrm{mg} \mathrm{kg}^{-1}\right)$ & $\mathrm{k}\left(\mathrm{d}^{-1}\right)$ & $\mathrm{T}_{1 / 2}$ & $\mathrm{C}_{0} / \mathrm{SOC}(\%)$ & $\mathrm{R}^{2}$ \\
\hline $\mathrm{CK}$ & $274.44 \mathrm{c}$ & $257.44 \mathrm{c}$ & $0.1671 \mathrm{a}$ & $4.15 \mathrm{~b}$ & $12.78 \mathrm{~b}$ & $0.9748^{* *}$ \\
$\mathrm{C} 1$ & $517.03 \mathrm{~b}$ & $526.05 \mathrm{~b}$ & $0.0824 \mathrm{~b}$ & $8.41 \mathrm{a}$ & $12.42 \mathrm{~b}$ & $0.9643^{* *}$ \\
$\mathrm{C} 2$ & $437.22 \mathrm{~b}$ & $484.61 \mathrm{~b}$ & $0.0697 \mathrm{~b}$ & $9.94 \mathrm{a}$ & $13.61 \mathrm{~b}$ & $0.9947^{* *}$ \\
$\mathrm{C} 3$ & $803.88 \mathrm{a}$ & $936.95 \mathrm{a}$ & $0.0622 \mathrm{~b}$ & $11.14 \mathrm{a}$ & $21.25 \mathrm{a}$ & $0.9983^{* *}$ \\
\hline
\end{tabular}

3 Notes: CK: the volume ratio of soft rock to sand is $0: 1 ; \mathrm{C} 1$ : the volume ratio of soft rock to sand is $1: 5$;

$4 \mathrm{C} 2$ : the volume ratio of soft rock to sand is $1: 2 ; \mathrm{C} 3$ : the volume ratio of soft rock to sand is $1: 1 . \mathrm{C}_{\mathrm{t}}$ for

5 amount of organic carbon cumulative mineralization, $\mathrm{C}_{0}$ for amount of potential mineralizable organic

6 carbon, $\mathrm{k}$ for constant of organic carbon mineralization rate, $\mathrm{T}_{1 / 2}$ for half turnover period, $\mathrm{C}_{0} / \mathrm{SOC}$ for

7 ratio of potential mineralizable organic carbon to total organic carbon in compound soil. Values followed

8 by different letters in the same column mean significant difference at 0.05 level between treatments, **

9 indicates a extremely significant level of $1 \%$. 
Figure 1

Test plot layout for soft rock and sand compound soils.

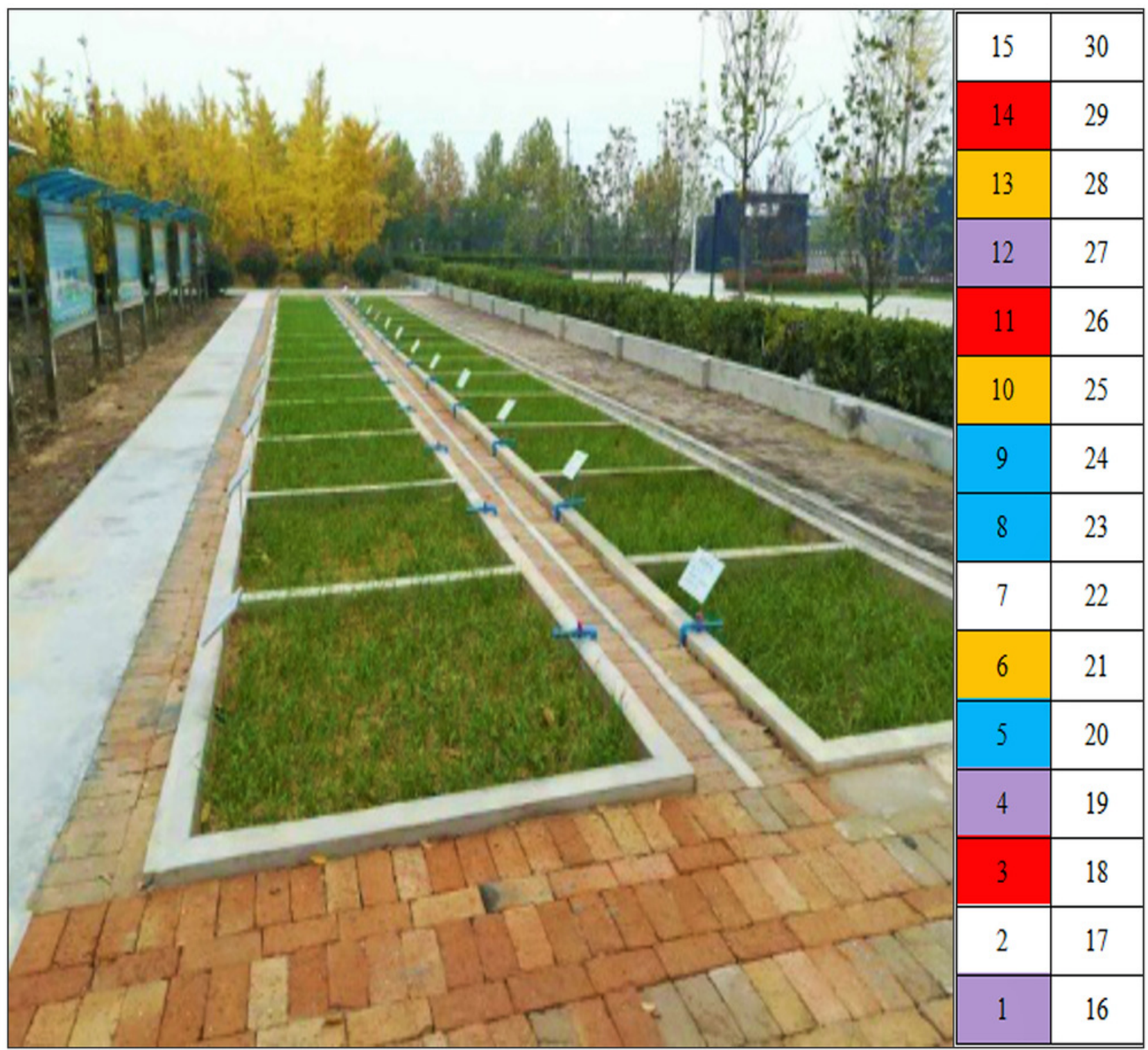


Figure 2

Organic carbon content of compound soils in different proportions of soft rock and sand.

Different letters above the bars mean significant difference (at 0.05 level) between

treatments. CK: the volume ratio of soft rock to sand is $0: 1 ; \mathrm{Cl}$ : the volume ratio of soft rock to sand is $1: 5 ; \mathrm{C} 2$ : the volume ratio of soft rock to sand is $1: 2 ; \mathrm{C} 3$ : the volume ratio of soft rock to sand is $1: 1$.

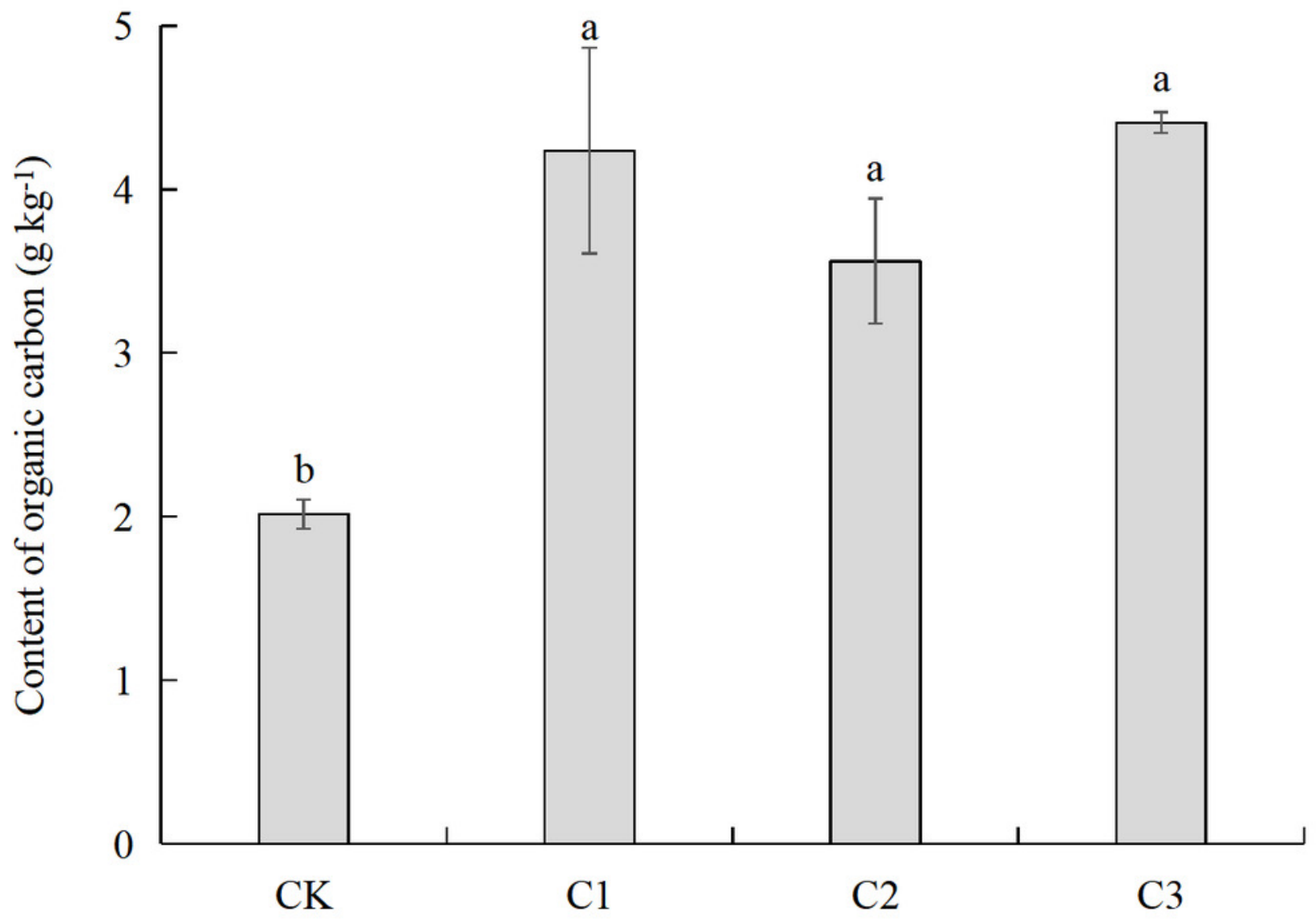

Treatments 
Figure 3

Organic carbon mineralization rate of compound soils in different proportions of soft rock and sand.

$\mathrm{CK}$ : the volume ratio of soft rock to sand is $0: 1 ; \mathrm{C} 1$ : the volume ratio of soft rock to sand is 1:5; C2: the volume ratio of soft rock to sand is $1: 2 ; \mathrm{C} 3$ : the volume ratio of soft rock to sand is $1: 1$.

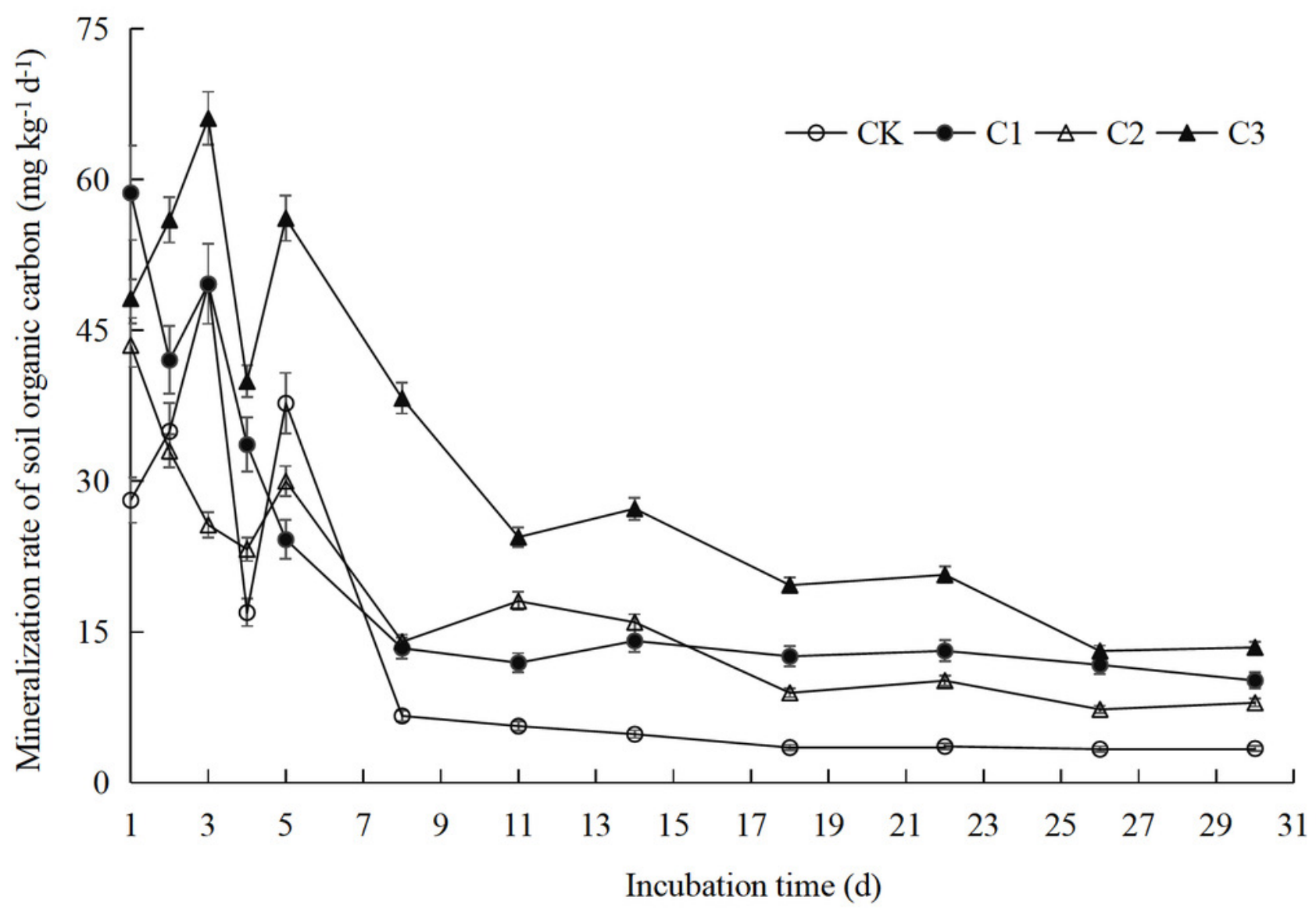


Figure 4

Organic carbon cumulative mineralization of compound soils in different proportions of soft rock and sand.

CK: the volume ratio of soft rock to sand is $0: 1 ; \mathrm{Cl}$ : the volume ratio of soft rock to sand is 1:5; C2: the volume ratio of soft rock to sand is $1: 2 ; \mathrm{C} 3$ : the volume ratio of soft rock to sand is $1: 1$.

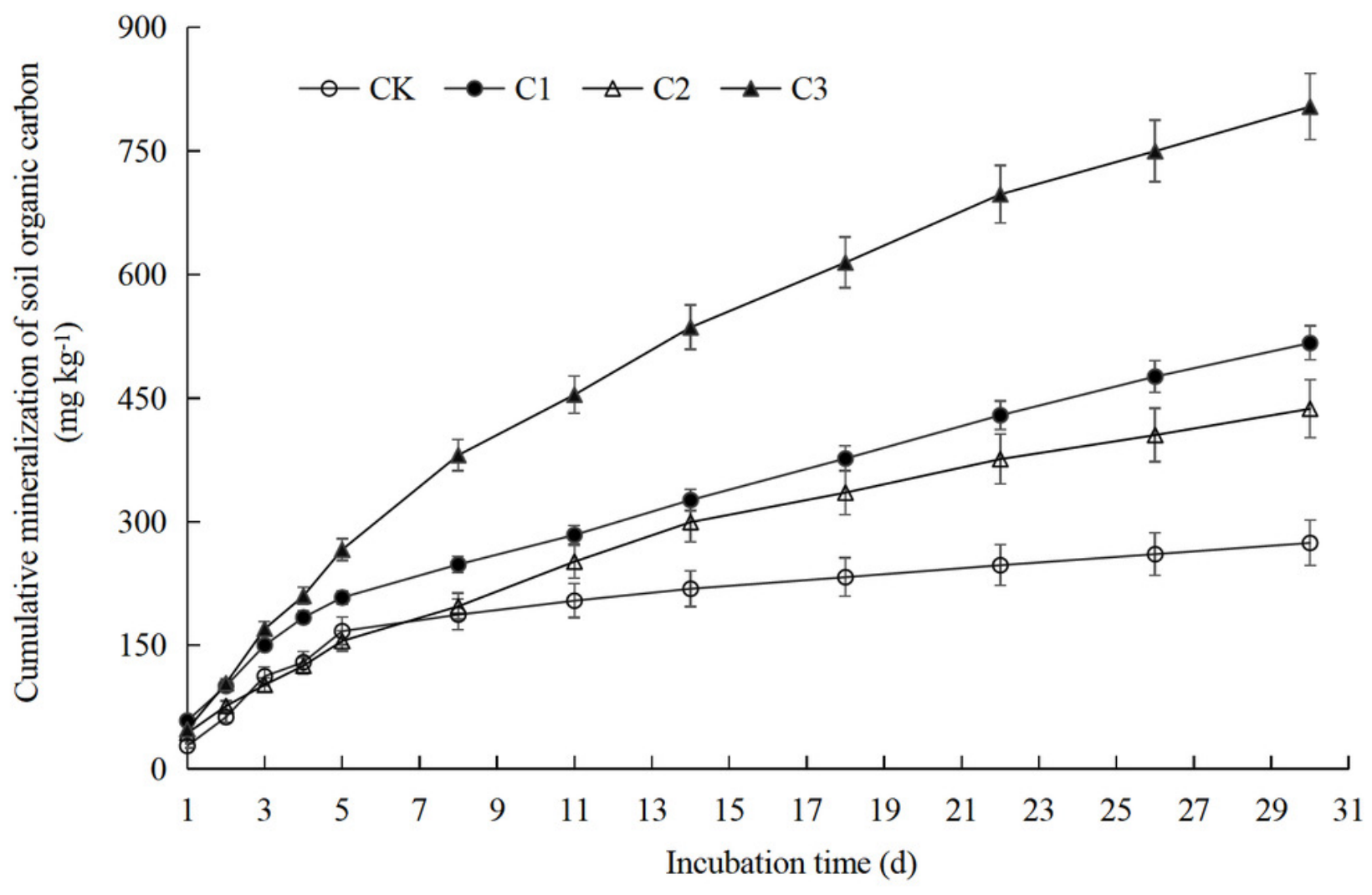


Figure 5

Cumulative mineralization rate of soil organic carbon under different compound ratios during the 30 days of incubation.

CK: the volume ratio of soft rock to sand is $0: 1 ; \mathrm{Cl}$ : the volume ratio of soft rock to sand is $1: 5 ; \mathrm{C} 2$ : the volume ratio of soft rock to sand is $1: 2 ; \mathrm{C} 3$ : the volume ratio of soft rock to sand is 1:1. Different letters above the bars mean significant difference (at 0.05 level) between treatments.

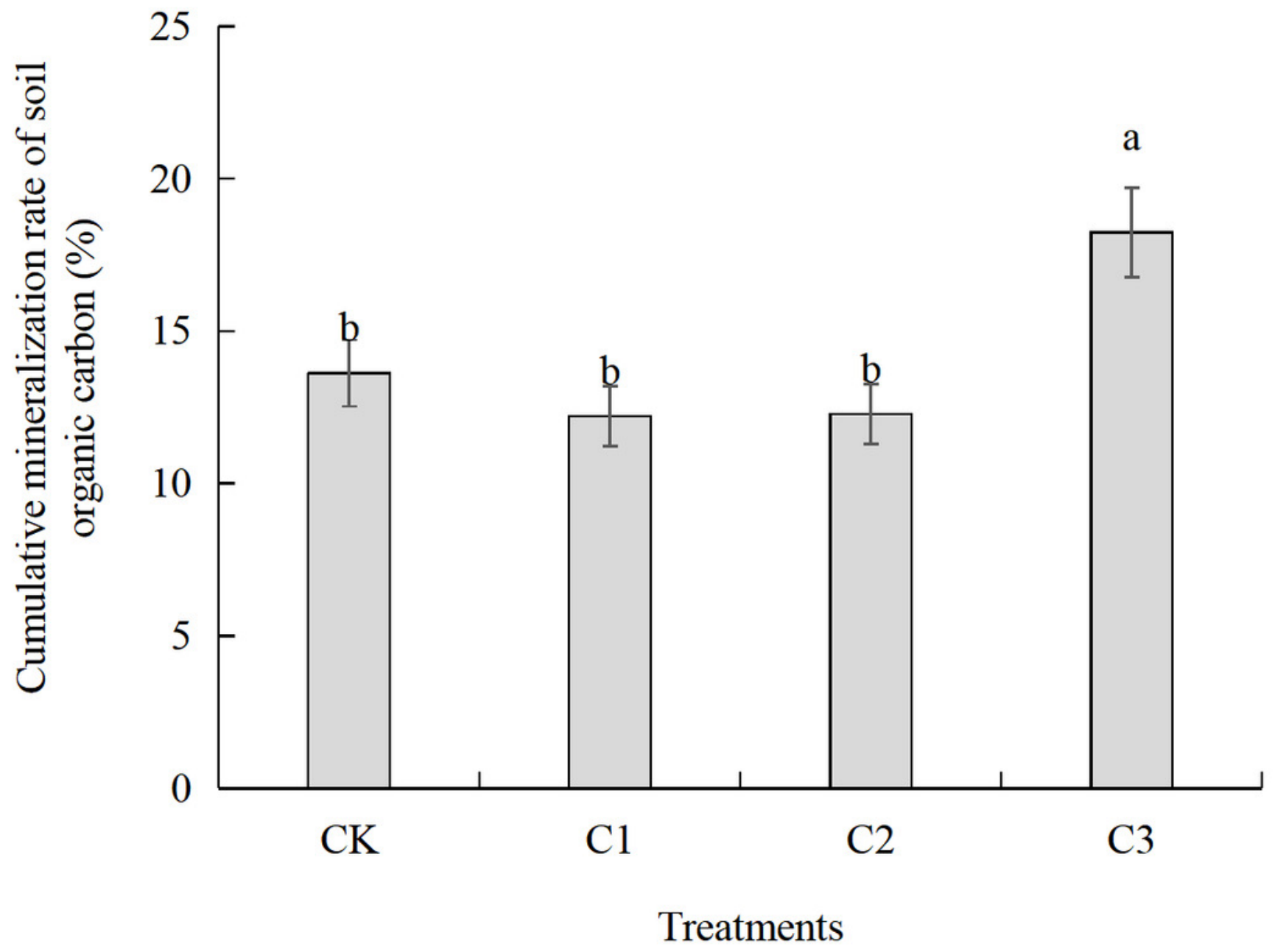




\section{Figure 6}

The microstructure of compound soil in different proportions of soft rock and sand.

(a): the volume ratio of soft rock to sand is 0:1 (CK); (b): the volume ratio of soft rock to sand is 1:5 (C1); (c): the volume ratio of soft rock to sand is 1:2 (C2); (d): the volume ratio of soft rock to sand is 1:1 (C3). The magnification is 1000 times.

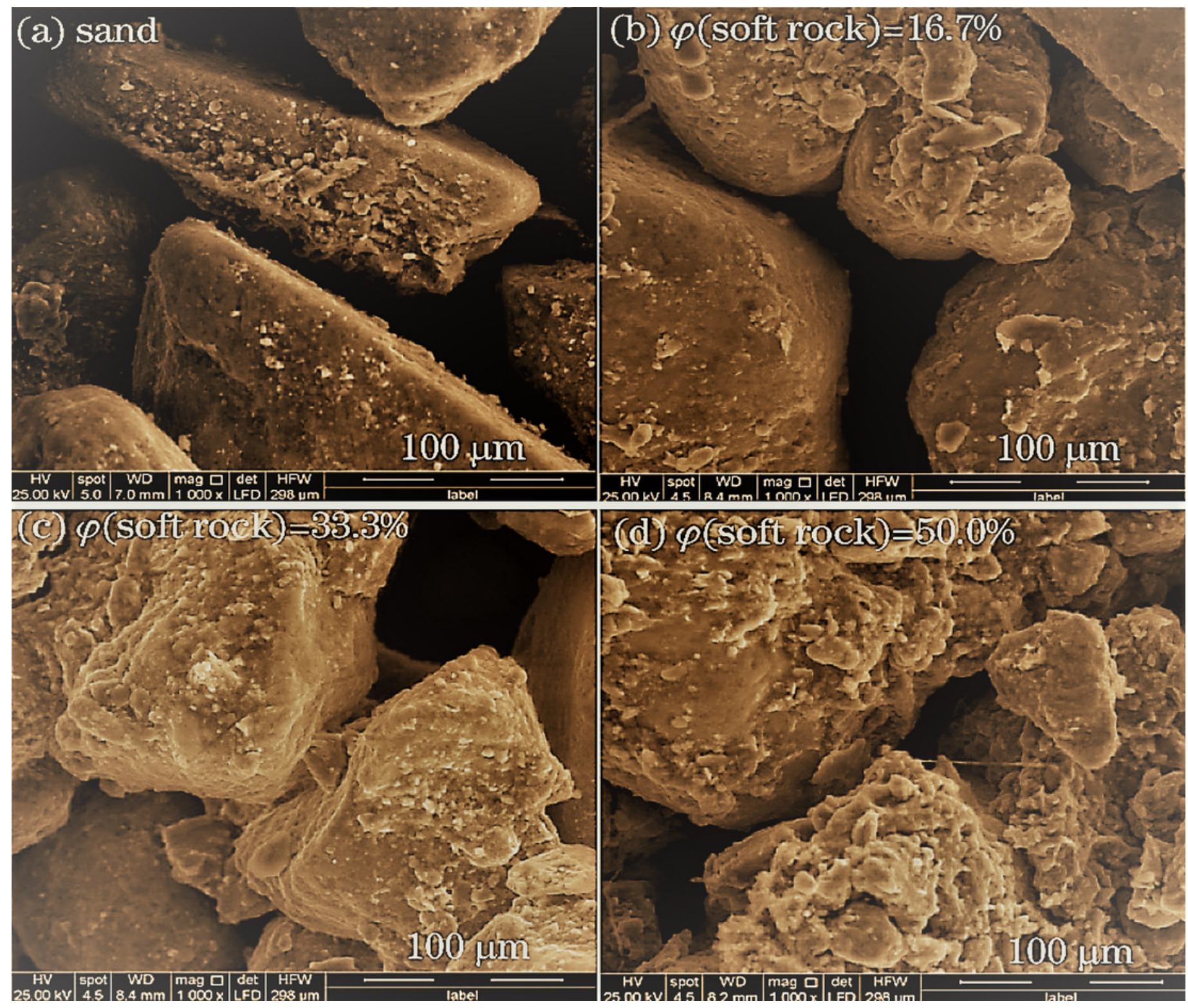


Figure 7

The soil particle composition under different compound ratios of soft rock and sand.

CK: the volume ratio of soft rock to sand is $0: 1 ; \mathrm{Cl}$ : the volume ratio of soft rock to sand is 1:5; C2: the volume ratio of soft rock to sand is 1:2; C3: the volume ratio of soft rock to sand is 1:1. Lowercase letters indicate significant differences (at 0.05 level) in the same particle composition between treatments.

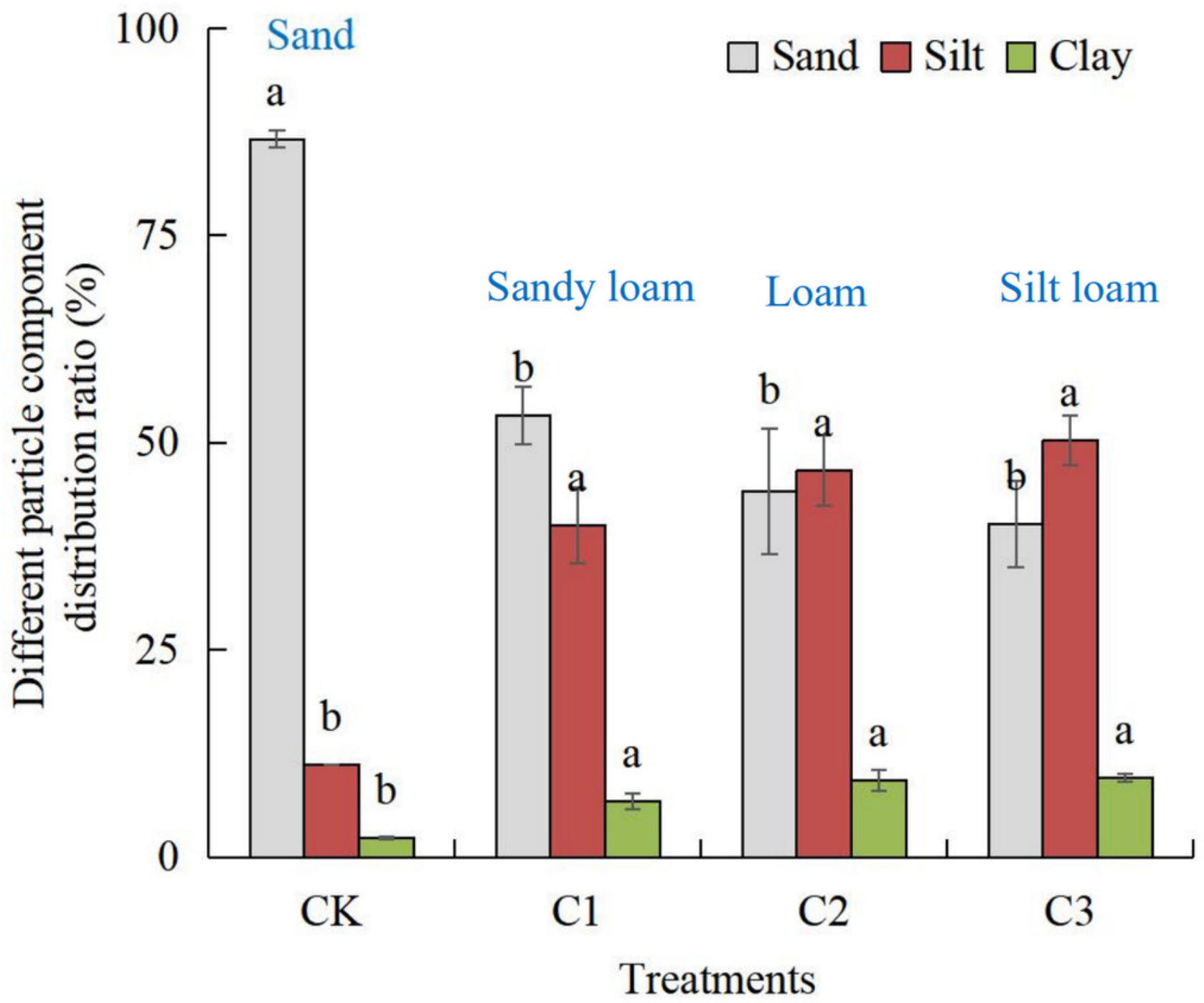

